\title{
An overview of the development of Personal Development Planning (PDP) and e-Portfolio practice in UK higher education
}

\section{Janet Strivens}

Centre for Recording Achievement and University of Liverpool, UK

\section{Rob Ward}

Centre for Recording Achievement, UK

\begin{abstract}
This article presents an overview of the origins of Personal Development Planning (PDP) in UK higher education and the development of the concept into a range of practices, rooted in the processes of recording achievement, reflection, review and planning. It reviews the various theoretical underpinnings that have been proposed for PDP and charts how the developing evidence base has become an increasing focus of interest to practitioners and policymakers alike. The role of technology in supporting PDP processes is acknowledged and in particular the close association between PDP and e-Portfolio practices is examined. The article concludes with a look at current initiatives which draw on PDP concepts, the continuing importance of these concepts to educational practice and the size of the research task which still lies ahead.
\end{abstract}

Keywords: Personal Development Planning (PDP); e-Portfolio; evidence-based practice.

\section{Introduction}

The origin of the current policy on Personal Development Planning (PDP) is the report by the National Committee of Inquiry in Higher Education, otherwise known as the Dearing Report (NCIHE, 1997). Recommendation 20 concerned Progress Files, a term that had recently been introduced in the 14-19 sector to replace the National Record of Achievement. It suggested that Progress Files should consist of two elements: 
- A transcript recording student achievement which should follow a common format devised by institutions collectively through their representative bodies.

- A means by which students can monitor, build and reflect upon their personal development (NCIHE, 1997).

Responsibility for the first element appeared to rest firmly with Student Records Offices and Registries, but this was less clear for the second element. Following acceptance by Government of this recommendation, alongside the 'steer' that this should be taken forward by the sector itself, the further elucidation of this element was taken on by Norman Jackson of the Higher Education Quality Assurance Agency (QAA), who instigated a national consultation, drawing largely on networks already established by the Centre for Recording Achievement (CRA). As an educational charity originally established as a project in 1991, whose purpose is to promote awareness and understanding of recording achievement processes as an important element in improving learning and progression throughout the world of education, training and employment' (see http://www.recordingachievement.org/), CRA was a natural partner in the consultation process.

What emerged from the consultation was, firstly, a term to describe Dearing's second element which has become widely accepted - Personal Development Planning. Secondly, a set of guidelines was published by the QAA, incorporating a definition of PDP which has become equally widely accepted:

A structured and supported process undertaken by an individual to reflect upon their own learning, performance and/or achievement and to plan for their personal, educational and career development. (QAA, 2001, 2009)

In the 2001 publication, formally published by the QAA, a set of minimum expectations for institutional PDP policies was set out. Students would be explicitly introduced to the rationale and opportunities for PDP at the start of the programme and provided with these opportunities at each stage of their programme. By the end of the programme they would have created their own learning records containing information on the qualities and skills which could be drawn upon as evidence when applying for a job or further study. They should be able to integrate extra-curricular experiences (voluntary service, part-time employment or work placements, study abroad, fieldwork and working as a student 
representative or student union officer) into their own PDP process. Institutions could offer accreditation and any such formal opportunities for PDP should be identified in the Student Transcript. Finally, institutions were expected to have mechanisms to assure themselves that PDP was being implemented effectively. Target dates for implementation were set: institutions should aim to have Transcripts available for students for the academic session 2002-3 and to have provided PDP opportunities for all students by 2005-6.

This guidance was not intended to constrain existing practice or local initiatives, indeed QAA expected that institutional or local policies would exceed these minimum requirements. However, crucially the nature and scope of opportunities for PDP and the strategies for recording and support were left to be determined by each institution. This was in line with existing realities - evidence suggested that much practice pre-dated Dearing and was essentially local and 'bottom-up' in origin (see for example Ward and Jackson, 2001).

Subsequently other policy initiatives have also emphasised the role of PDP-style practice. In 2005 the Higher Education Funding Council for England (HEFCE) in its e-Learning Strategy encouraged 'e-based systems of describing learning achievement and personal development planning' (HEFCE, 2005, p.13), and the Department for Education and Skills in its e-Strategy supported the greater 'personalisation' of learning across all educational sectors:

We will encourage every institution to offer a personal online learning space to store coursework, course resources, results and achievements. We will work towards developing a personal identifier for each learner, so that organisations can support an individual's progression more effectively. Together, these facilities will become an electronic portfolio, making it simpler for learners to build their record of achievement throughout their lifelong learning. (DfES, 2005, p. 5, para10)

\section{What is meant by PDP?}

Notwithstanding the definition provided within the guidelines and cited above, the emphasis upon 'situated practice' sensitive to local meaning and realities inevitably runs a 
risk: confusion can be created by using the term Personal Development Planning without qualification because such a broad range of aims and activities are encompassed by the term. Recognising this problem, Grant and Richardson (nd) collected information from over thirty institutions on typical activities and outputs associated with the PDP processes. This yielded two lists, of thirty-three activities recognised by the sector as relevant to PDP, and forty-nine types of record (including the learner's personal details) which might be generated as a result of these activities. These can be grouped into the following areas (with some overlap):

- Recording experiences and achievements.

- Thinking about skills.

- Thinking about values, attitudes, motivations, reasons.

- Goal-setting and planning.

- Summarising (for presentation to a third party).

- Understanding oneself as a learner.

The activities associated with recording experiences and achievements are compiling, describing and reviewing. Records include learning logs and reflective writing about past experiences - narrative, descriptive writing and also analysis. Thinking about skills includes audits, self-assessments, recognising skills in experiences, associating evidence with skills and planning for skill development. Thinking about values, attitudes, motivations and reasons is somewhat similar, but instead of a skills framework, activities might include sets of questions intended to help the learner clarify values, preferences and goals. These could range from highly structured inventories such as careers guidance questionnaires to much broader questions aimed at increasing self-awareness. GoalSetting and Planning might need to draw on previously identified preferences and provide advice on pathways. The learner would be engaged in setting targets and a timeframe. Summarising for presentation includes the activities of CV writing and developing e-Portfolios for showcasing. It involves the learner in selection of evidence (and therefore judgements about the quality of evidence) and may call upon design skills. It may also involve researching careers and other opportunities for progression, and matching requirements to previously identified preferences, values, skills and achievements. Understanding oneself as a learner might consist of a series of prompts to help the learner think about their learning preferences. Some practitioners use learning styles 
questionnaires although these need to be selected with caution, as a major report on the evidence base for different models of learning styles makes clear (LSRC, 2004).

In their 2005 survey on progress towards full implementation (see below), Ward et al. report a similar list of activities identified by the almost three hundred staff who took part in the consultation:

- Thinking ahead and planning, using both critical rational thinking and imagination.

- Doing something and being more aware of what is being done.

- Recording these observations and perceptions.

- Reviewing/reflecting on actions and their effects.

- Evaluating and making judgements about self and the effects of own actions.

- Engaging in conversation with a teacher/tutor and/or peers in order to discuss/challenge experiences, perceptions and judgements.

- Using this personal knowledge as a resource to inform future actions (Ward et al., 2005, p.3).

Most recently Peters and Tymms (2010) have further unpacked the concept of PDP, returning to the 'structured and supported' definition cited above and analysing each word or phrase thus:

- Process: PDP is a verb not a noun. It is an ongoing educational process not a document or file.

- Individual: the focus is upon, and the responsibility lies with, the learner her/himself.

- Structured: it is a process that involves a number of stages that build upon each other.

- Supported: though the focus is on the individual learner it is not undertaken alone but with help from tutors, colleagues and institutional systems.

- Reflect upon their own learning, performance and/or achievement, and to plan: suggests a number of elements of the PDP process and relates to the EPPI-Centre systematic literature review's chosen definition of PDP, for the purposes of their search, as 'processes that connect reflection, recording and action planning' (Gough et al., 2003, cited Peters and Tymms, 2010). 
- Personal, educational and career development: emphasises the three spheres of learning that PDP draws together, helping to make connections between the development of the individual, their educational experiences and life choices. (Peters and Tymms, 2010, p.10)

\section{How far have we come with PDP implementation?}

In November 2003, the Centre for Higher Education Research and Information (CHERI) published an interim report on progress towards implementation (Brennan and Shah, 2003). The CHERI survey highlighted the range of approaches taken by Higher Education Institutions (HEIs) in implementing the QAA Guidelines. Their main findings were that:

- PDP policies were often varied in approach, and such policies had been introduced by fewer than half the institutions that responded.

- Progress in implementation was slow and uneven, and there was a lack of common understanding about PDP.

- Perhaps because of this and the difference in institutional mission and ethos, PDP was related to a range of institutional policies. Employability was identified as the most frequently perceived driver to adoption (61 out of 73 respondents) followed by inclusion within quality assurance reference points (55), retention (39), and widening participation (39).

Subsequently, Ward et al. (2005) carried out a consultation through a workshop programme to assess progress towards implementation. This also found that, at institutional level, PDP policies were predominantly permissive in nature and based upon broad frameworks with opportunities for local interpretation. This reflected the QAA policy position that the 'application of Personal Development Planning should be based on institutionally determined policies within a national guidance framework' (QAA, 2000). The legitimisation of locally derived and developed practice provided the predominant strategy for implementation, with centrally derived/developed approaches often intended to serve as a default or minimum expectation within an institution.

Links between the twin elements of the Progress File (Transcript and PDP) were limited. The prevailing view was that, while there may be connections at the level of institutional 
policy, the picture 'on the ground' was that Transcript and PDP development work were running relatively independently (a minority of institutions suggested that, where IT-based systems were in place or under development, the potential to integrate the two aspects of policy was stronger). There was also little evidence of policy refinement based upon evaluation evidence.

For the practitioners, PDP was seen as a holistic and integrated set of processes, with a consistent emphasis on the role of PDP processes in the development of student selfidentity, broadly conceived. PDP outputs were seen as records of this process, and as raw material on which students could draw when presenting/ representing themselves to others. However, in programmes where PDP-style activities were required for professional recognition or progression, the records themselves assumed a primary public (or at least shared) purpose. Connecting higher education practice with that taking place elsewhere (pre-higher education experience in schools/colleges, requirements of employers and professional bodies) was seen as important. Practitioners also felt that the definition of PDP contained within the Policy Guidelines remained broadly fit for purpose.

In 2008, CRA carried out a further survey to try to establish the different modes of PDP and their prevalence in higher education provision. Of eighty-five respondents, around three-quarters stated that their institutions had a written policy on PDP and that PDP was referred to in the institution's Learning andTeaching Strategy documentation. Over half the institutions represented had a special team with a PDP remit. At undergraduate level $43 \%$ claimed that PDP was 'mostly established', 16\% that it was 'very well established'. The percentage was higher at postgraduate level (above 60\%) which was not surprising in the light of the Roberts funding for postgraduate skills training (Roberts, 2002).

This survey indicated that few institutions required a single mode of PDP provision across the whole institution. In relation to the degree of compulsion on students to become involved in PDP, over two-thirds of respondents claimed that PDP activities were assessed in their institution. Over $80 \%$ of respondents said that PDP was embedded in creditbearing modules in at least some curriculum areas, however, 70\% said that PDP was also delivered outside the curriculum for some students, typically through personal tutors. There was strong support (over 80\% agreement) for the notion that PDP should be adapted to different curriculum areas rather than reflecting a single imposed model. $60 \%$ of respondents also said that their institution offered some form of programme outside the 
formal curriculum, such as a skills award - a percentage which is likely to have increased since the survey was carried out (see for example 94 Group, 2009). While the survey suggested that PDP was increasingly accepted as a part of the student experience which the institution was responsible for providing, a note of caution was struck by the finding that two-thirds of respondents thought that staff still saw PDP as an increase in workload.

More recently there appear to have been moves towards more structured institutional frameworks and support for PDP, whether in respect of policy or on staff support (see University of Bolton (2005) for an example of policy and University of Bristol (2009) for examples of a range of staff guides).

\section{Supporting PDP with e-Portfolio (and other) technology}

A further survey carried out by CRA for the Higher Education Academy found that from sixty-one UK HEls responding, over half were using some form of technology (other than an e-Portfolio) to support PDP institutionally (Strivens, 2007). In response to another question, the same proportion claimed to have access to an e-Portfolio system, often as a pilot, and the main reason given for acquiring an e-Portfolio tool (again by over half of respondents) was to support PDP. These findings illustrate the strong tendency in UK higher education to associate e-Portfolio (technology and practices) with PDP practices (see also Strivens et al., 2010). This is understandable. PDP calls for reflection; ePortfolios claim to support it. PDP highlights the explicit acknowledgement and recording of personal achievement; e-Portfolios provide a means of storing and displaying the evidence. So what is an e-Portfolio?

Most writers on e-Portfolios acknowledge that attempts at definition are fraught with difficulty (see for example Stefani et al., 2007; Grant, 2009). The JISC Infokit on ePortfolios comments 'ideas of what an e-Portfolio 'is' are complex and to an extent the definition and purpose will vary depending on the perspective from which a particular person is approaching the concept' (JISC, 2009). There are a number of reasons for this. Firstly, the target is moving as the technology itself develops continually. E-Portfolios are still, in 2010, a relatively new technology (the first European conference devoted to ePortfolios was held in 2003, although US practice somewhat pre-dates this). Different systems which are referred to as e-Portfolio systems may offer a different range of 
functionalities. More confusingly, some use the term 'e-Portfolio practices' loosely to describe pedagogies designed around reflection, underpinned by different tools with a more restricted functionality such as a blogging tool. As the JISC publication 'Effective Practice with e-Portfolios' (JISC, 2008) points out, the term is increasingly used to refer to both product and process. The product is a 'purposeful aggregation of digital items' (JISC, 2008, p.6) in some form of repository. Multiple e-Portfolios might be created from the same repository or set of repositories for presentation to different audiences. Behind this lie ' rich and complex processes of planning, synthesising, sharing, discussing, reflecting, giving, receiving and responding to feedback' which may be referred to generically as 'e-Portfoliobased learning' (JISC, 2008, p.6).

Secondly, e-Portfolios have developed more or less simultaneously within different cultural and educational traditions. The emphasis on personal celebration in the US tradition can seem alien to some UK practitioners: conversely assessment in US HEls seems less driven and constrained by an externally imposed quality regime than with their UK and Australian counterparts. The practice which is presented to showcase what e-Portfolios can offer thus varies somewhat in its emphasis between countries.

If a single agreed definition remains problematic, there is certainly mutual understanding of the common features of e-Portfolio systems. Grant (2009) introduces e-Portfolio technology as being suitable for analysis along the three dimensions of purpose, information and functionality. He notes that common functionality seen in e-Portfolio tools includes input of and storing information both from the learner and from others; managing and organising artefacts and information, including tagging and constructing linked narratives; and setting varied permissions to several people or groups for viewing and giving feedback. In the assessment context, any of this information could potentially be seen as useful evidence of the learner's abilities.

The concept of a portfolio as the holder for an individual's collection of artefacts has a long-established history, especially in art and design disciplines. The large majority of ePortfolio tools are capable of holding electronic artefacts authored by the learner, including office tool files, photos and graphics, and possibly audio and video files - though sometimes it is expected that these are stored by a third party service provider such as YouTube - as well as the reflections and narratives that are increasingly recognised as relevant to assessment. 
In 2007, a JISC overview paper identified a generally accepted range of purposes: application (to employment or further study); supporting transitions; for learning, teaching and assessment through supporting reflection, discussion and formative assessment, and providing evidence for summative assessment; personal development planning (PDP) and continuing professional development (CPD) (JISC, 2007). This range is also recognised in the 'Effective Practice with e-Portfolios' (JISC, 2008) publication.

As noted above, e-Portfolios have been closely identified with PDP policy in UK higher education as the tool of choice to support PDP processes. However, there may be some drawbacks to this tight association. The use of e-Portfolios as a vehicle for more innovative and imaginative forms of assessment has much potential, still largely unexplored (see Strivens et al., 2010). Where there is institutional apathy or cynicism about the value of PDP, this may transfer to the technology most associated with it and inhibit more widespread adoption.

\section{Using technology to support PDP: benefits and drawbacks}

As the 'structured and supported' emphasis within the PDP definition makes clear, learners will need varying degrees of help with all types of PDP activities, depending on their experience and maturity. Help and guidance can be provided by tutors, mentors and careers advisers but these are expensive and scarce resources in most HEls. Rather than using an integrated e-Portfolio system, some institutions have developed electronic resources on websites to provide at least some of this support, coupled in some cases with a secure means of storing the records generated throughout the process.

Indeed there are a range of technologies which can play an important role in supporting PDP processes. Insofar as PDP activities are learning activities, technologies which are explicitly designed to support a series of these would appear to be of value. It is noticeable that in UK higher education, one development of e-Portfolio systems has been in the direction of providing templates to guide the learner into producing a reflective statement, record or commentary. The templates are arguably not part of the e-Portfolio itself, they function more as a set of guidelines or rubrics to make sure that the learner produces what is required. This is perfectly reasonable thinking in terms of curriculum design and also when e-portfolios are used as a vehicle for assessment, as in many professional areas. 
However, it is somewhat at odds with the concept of the e-Portfolio (which features strongly in some definitions) as owned by its user, containing artefacts chosen by the user and displayed selectively according to that user's permission.

Linked to the question of ownership, another important issue which institutions need to address is what happens when the student leaves the institution. Where e-Portfolio systems store evidence of achievements, helpful information about preferences and abilities and practice CVs, learners will need and wish to access this material beyond the boundaries of a specific programme. It must either be stored by the institution with continuing access rights for the learner, transferred into another institution's system or downloaded in a usable form. Some of the problems around this are technical but more are to do with the institution's own policy.

Electronic systems have some distinct advantages over paper-based recording systems. The records are harder to misplace and the administrative burden for staff members is likely to be eased. Links to online help and guidance (for both students and staff) can be easily incorporated. The structure of an online system can help students through different aspects of the PDP process, presenting helpful questions and prompts for reflection, providing reminders and timelines for planning and reviewing.

Disadvantages include differential access to technology outside the academic environment and differences in IT skills themselves which can discriminate against and even exclude some groups of students. Within institutions information systems may not communicate with each other, leading to the need to re-enter the same information several times in different systems which causes confusion and rapid de-motivation. More seriously, when students are work-based or participate in extensive work placements, institutional firewalls or issues of confidentiality may prevent access from outside, effectively preventing the integration of learning across contexts (see below).

\section{Developing our understanding of e-Portfolio practice}

Given the uncertainties and varying strands of development outlined above, research into the impact and effective use of e-Portfolios faces particular challenges. In 2010, at an international seminar bringing together practitioners from the US, the UK, Europe and 
Australasia, Cambridge and Hartley (2010) suggested a list of twelve 'things we think we know' about e-Portfolios. The list actually included a number of 'don't knows' which echo the above uncertainties:

- Different e-Portfolios offer very different underlying assumptions/approach and organisation.

- E-Portfolios need ongoing (and long-term) support from staff and the institution (including an appropriate degree of training and familiarisation.

- We do not have a shared or absolutely coherent definition of what an e-Portfolio actually is.

- There are different 'cultural traditions' which affect both the adoption and uptake of PDP and e-Portfolios.

- Some students on some courses benefit significantly from PDP activities which are managed through e-Portfolio.

- E-Portfolio authors must have control over the construction and visual design of their portfolios.

- The e-Portfolio genre is especially valuable for synthesising experiences across contexts, both academic and otherwise, and for cultivating professional and disciplinary identities.

- E-Portfolios can/may have impact on student engagement and retention;

- The role of the academic tutor is absolutely critical to the successful adoption of both PDP and e-Portfolios by students.

- Tutors use e-Portfolios in very different ways.

- E-Portfolios have varying efficacy for certain types of assessment.

- E-Portfolios must have an articulated and coherent educational philosophy to guide practice.

In putting together this list, Cambridge and Hartley acknowledge the real challenges of the e-Portfolio research agenda, 'what we need to know':

- The long-term impact of e-Portfolio adoption/use (how should this be evaluated?).

- Whether we can expect one e-Portfolio to suit every student (or even the majority of students). 
- The underlying psychological processes that support or impede the take-up of ePortfolios, for both staff and students.

- The importance of IT skill and confidence.

- How reluctant tutors can be persuaded or encouraged.

- The most significant institutional barriers and enablers.

- A better understanding of the multiple audiences for e-Portfolios (not just students and tutors).

Cambridge and Hartley speculate that meeting these challenges will require a broader range of methods and approaches (crucially involving more observation of behaviour and less self-report), but methods and approaches shared across the e-Portfolio community of practice so that data can be compared across institutions.

It may be an indication of the accuracy of Cambridge and Hartley's analysis that many of their key issues are addressed in recent and current research. A current JISC project (Joyes and Smallwood, 2010) is studying large-scale implementations of e-Portfolios within institutions, looking at barriers and enablers. A recent JISC project (Coolin et al., 2010) offered institutions and learners a range of different products, noting their preferences and purposes for use. Globally the 'community of practice' is developing a sense of identity and constantly improving opportunities and methods for pooling and exchanging their developing knowledge and experience.

\section{Evidence for the effectiveness of PDP in achieving its aims}

In the 2005 consultation already described, the development of an evidence base for the benefits of PDP was identified as one of four key priorities for practitioners. This reflected the continuing recognition that studies have often been highly context-specific evaluations, focusing on acceptability to staff and students of local procedures and tools. In such cases it has been difficult to generalise from the variety of methods and instruments used and there has been little focus on outcomes, perhaps because this is still a relatively recent innovation in most institutions. The work of the NARN, as reported upon in this special edition, goes some way toward addressing this. 
There are at least three major challenges around evaluation of PDP processes and portfolio systems in the support for learners. Firstly, in a conventional educational setting it would normally be unethical to design an educational empirical study with groups of learners, some of whom were exposed to the support intervention (experimental groups), and others who were denied it (control groups). Instead, most studies rely on observation of naturally occurring data. Secondly, it is generally not possible with such naturally occurring data to attribute changes to a particular intervention, rather than to a general effect of 'any' intervention. Thirdly, where studies demonstrate a correlation between two factors this does not of itself imply a causal direction. Thus, outcomes from Peters' (2006) study, carried out as part of his National Teaching Fellowship, showed that across the six very different institutions which took part in the research, there was a statistically significant relationship between students' willingness to engage in PDP processes and their ultimate degree classification.

Similarly Clark et al. (2010) reported that comparison of 'scores' on the Effective Lifelong Learning Inventory (ELLI) (see http://www.ellionline.co.uk/) achieved during the first year of the degree course with those of the same students at the end of the second year module, with reference to reflective writing ability, indicated that those who engaged with the PDP/e-Portfolio process (that is, those whose reflective writing showed deeper thought) showed most positive change. Those who did not engage, however, showed a decrease in learning 'power' in those three ELLI dimensions identified as having a significant correlation with high achievement (Critical Curiosity, Changing and Learning and Strategic Awareness). While such outcomes as these do not of themselves provide support for a causal relationship, they do merit further investigation.

Notwithstanding these caveats, the international research synthesis undertaken by Gough et al. (2003) provided evidence for positive effects of processes linking reflection, recording and planning on improving students' learning. The study which undertook a systematic mapping and synthesis of PDP-related research screened 14,000 studies for review, of which 157 met the inclusion criteria for the review. These were keyworded to produce a systematic map of research activity in the field, and twenty-five selected for indepth review on the basis of researcher intervention and independent outcome measures, such as knowledge, approaches to learning styles or self-review. The papers were judged on the quality of research and weight of evidence and the outcome assessment was that PDP had a generally positive influence on improving student learning. Although this 
judgement was based on a small number of studies, the authors concluded there was good evidence of a strong association.

Building on this prior work, and as a continued recognition of the importance of the evidence base for PDP and e-Portfolio policy and practices, over the past three years two research networks have been in existence, each devoted to furthering research in these areas. Cohort 5 of the Inter/National Coalition for EPortfolio Research was the first cohort of this US-based initiative to be primarily UK-based, with seven of its nine institutional members from the UK. Research outputs from all cohorts to have completed their work so far are available on the I/NCEPR website (see http://ncepr.org/).

Over approximately the same period of time, the work of the National Action Research Network on researching PDP and e-Portfolio practice has brought together seventeen institutions in England, building research capacity amongst practitioners and exploring a range of issues in PDP practice in UK higher education. Whilst the emphasis has remained substantially, and appropriately, upon seeing PDP practice as highly situated and responsive to local circumstances, the emphasis here has been upon more considered and rigorous approaches to such investigation, carried out within a community of practitioner-researchers who have been able to support and challenge one another in the development of more systematic approaches to research and evaluation, and in the processes of analysis and interpretation of results.

\section{Looking to the future}

The QAA's revised Guidelines to support Personal Development Planning identified a range of developments in the UK higher education sector since the formulation of the original Guidelines in 2001 (QAA, 2009, para.14). An increased reference to PDP approaches in subject benchmark statements was noted, as documented by Atlay (2008). Here we emphasise three further developments which focus upon the extension of PDP practices - in two cases - and the potential for further mainstreaming in the third.

In relation to postgraduates, the 2008 survey carried out by CRA reported substantial progress in this area. This was facilitated by the Roberts' Review, SET for Success (Roberts, 2002). Subsequently the QAA Code of Practice (2004, p.12) related to 
postgraduate research programmes set out the expectation that learners will take 'responsibility for their own personal and professional development'. Most recently a consultation on the Researcher Development Framework identified the production of 'a tool for planning, promoting and supporting personal, professional and career development' as a key project aim (Vitae, 2009, Slide 3). Work is currently (November 2010) proceeding to develop this initiative.

Elsewhere PDP practice appears ever more central to the developing employer engagement agenda (Leitch, 2006). Flexibility in when and where learning is taking place, including increased work-based learning, underlines the importance of electronic delivery. Specifically, while the Leitch agenda was well sketched out at the macro level, to work in practice it requires the development of effective and worthwhile learning practices within distributed learning environments (the workplace) which are simultaneously personalised to the learner and appropriately connected to organisations and organisational needs and requirements (Richardson and Ward, 2007). The role of e-Portfolio technologies in support of this agenda is explored in the major policy project undertaken by CRA for the HEFCE in 2009-2010 (see the Higher Education Employer and Employee Engagement through EPortfolios (HE5P) Project at http://www.recordingachievement.org/employerscpd/he5p.html).

Finally, a key current policy initiative is the development of the Higher Education Achievement Report (HEAR). In October 2003 the Measuring and Recording Student Achievement Scoping Group was established by Universities UK and the Standing Conference of Principals (SCOP), with the support of HEFCE, to review the recommendations from the UK Government White Paper, The Future of Higher Education, relating specifically to recording student achievement, value added, degree classifications and credit systems. The final report from the Burgess Steering Group recommended that:

- By 2010/11 a Higher Education Achievement Report (HEAR) will be the central vehicle for recording all university-level undergraduate higher education student achievement in all UK higher education institutions.

- The HEAR will contain information which the institution is prepared to verify. Further work should be done on how to measure and record skills and achievements gained through non-formal learning but this, along with 
other student-generated/driven information, should be part of Personal Development Planning (PDP). (Burgess, 2007, p.9)

Whilst the 2007 report explicitly emphasised that PDP and the HEAR should be seen as distinct though complementary, subsequent work has served to emphasise the potential for interrelationship and synergy. Thus, amongst institutions piloting the HEAR the conception has served to invite reconsideration of learning and teaching including more holistic appreciations of learning and achievement (revisiting the graduate attributes agenda - see HEQC 1997a, 1997b). The emphasis upon a richer record of graduate achievement inevitably promotes consideration of aspects of life-wide learning and how achievements in this wider terrain may be verified and accredited. The HEAR further invites renewed consideration of the relationship between institutionally-managed and learner-managed information, the latter as held in e-Portfolio systems for example. One perspective, expressed within the HEAR trial, has represented this in terms of the HEAR sitting behind the presentational portfolio or application made by any graduate, as a means of verifying the claims/attestations made. Such a relationship would imply a direct link from any application or presentational portfolio into the individual's summative HEAR.

From this perspective also, HEARs initiated at entry to the institution and developed through the student's career may provide a context for recognising learning and informing choices. Where PDP opportunities are offered through a personal tutoring system, such processes are deeply familiar. As another institution in the HEAR pilot reports:

The University of Manchester is exploring formative HEARs to be produced annually for students in order to inform their academic and extra-curricular choices. The 'HEARing Student voices' project will focus on the formative, development aspects of the HEAR initiative and will run alongside the development of graduate HEARs (University of Manchester, 2009).

In summary, the concept and vision of PDP appears to have become embedded in thinking about higher education policy in the UK. Associated practices have developed internationally, with a range of aims from the full development of individual potential or the lifelong upskilling of the national workforce. E-Portfolio technologies continue to spread, with many institutions seeing e-Portfolio provision for all students, and staff, as a strong 
marketing tool. Still, many questions remain, particularly around achieving the widest possible learner engagement with both processes and supporting technologies. The field remains one with enticing visions and possibilities alongside many frustrations in implementation; rich in opportunities but with much work still to be done before they are fully realised.

\section{References}

94 Group (2009) Beyond the curriculum: opportunities to enhance employability and future life choices. Available at: http://www.1994group.ac.uk/documents/public/091106 BeyondTheCurriculum.pdf (Accessed: 3 November 2010).

Atlay, M. (2008) Subject benchmarks and PDP: a review. Available at: http://www.recordingachievement.org/higher-education/articles/item/highereducation-articles/subject-benchmark-statements-and-pdp-a-review.html (accessed 3.12.10).

Brennan, J. and Shah, T. (2003) Report on the implementation of progress files (CHERI Review). Available at: http://oro.open.ac.uk/324/1/ProgressFiles.pdf (Accessed: 3 November 2010).

Burgess, R. (2007) Beyond the honours degree classification: final report of the Burgess Group. Available at:

http://www.universitiesuk.ac.uk/Publications/Documents/Burgess final.pdf (Accessed: 3 November 2010).

Cambridge, D. and Hartley, P. (2010) 'E-portfolios: what do we know and what do we need to know?', 2nd International Residential Seminar 26th - 28th April 2010.

Nottingham. Available at http://www.recordingachievement.org/images/pdfs/case studies/post event/darrenp eter.pdf (Accessed: 3 November 2010). 
Clark, W., Adamson, J., Thompson, J., and White, A. (2010) 'Illuminating and measuring personal development: the impact of this work on learning and teaching', PDP and e-Portfolio UK Newsletter Issue 20, September 2010. Available at: http://www.recordingachievement.org/news-and-events/publications/pdpuk.html (Accessed: 3 November 2010).

Coolin, K., Harley, P., Smallwood, A. and Wood, S. (2010) ePortfolios and lifelong learners: report of the Leap Ahead Lifelong Learning Network ePortfolio/eSystems Strand, Centre for International ePortfolio Development. Nottingham: University of Nottingham.

DfES (2005) Harnessing technology: transforming learning and children's services. Available at: http://www.dfes.gov.uk/publications/e-strategy (Accessed: 3 November 2010).

Gough, D.A., Kiwan, D., Sutcliffe, K. and Simpson, D. (2003) A systematic map and synthesis review of the effectiveness of personal development planning for improving student learning. London: EPPI-Centre, Social Science Research Unit. Available at:

http://eppi.ioe.ac.uk/EPPIWebContent/reel/review groups/EPPI/LTSN/LTSN June0 3.pdf (Accessed: 3 November 2010).

Grant, S. (2009) Electronic portfolios: personal information, personal development and personal values. Oxford: Chandos Publishing.

Grant, S. and Richardson, H. (nd) Personal development planning practice and systems. Available at: http://www.cetis.ac.uk/members/PDPcontent/viewActivityTypes (for activities) and http://www.cetis.ac.uk/members/PDPcontent/viewPartTypes (for outputs/records) (Accessed: 3 November 2010).

HEFCE (2005) Strategy for e-Learning. Available at: http://www.hefce.ac.uk/pubs/hefce/2005/05 12/05 12.doc (Accessed: 3 November 2010). 
HEQC (1997a) Assessment in higher education and the role of 'graduateness'. London: Higher Education Quality Council.

HEQC (1997b) Graduate standards programme final report: volume 2. London: Higher Education Quality Council.

JISC (2007) E-portfolios: an overview of JISC activities. Available at:

http://www.jisc.ac.uk/publications/documents/pub eportfolio overview.aspx (Accessed: 3 November 2010).

JISC (2008) Effective practice with e-Portfolios. Available at:

http://www.jisc.ac.uk/publications/publications/effectivepracticeeportfolios.aspx (Accessed: 3 November 2010).

JISC (2009) E-Portfolios. (JISC Infonet). Available at:

http://www.jiscinfonet.ac.uk/infokits/e-portfolios (Accessed: 3 November 2010).

Joyes, G. and Smallwood, A. (2010) e-Portfolio Implementations Study (ePI). Available at: http://www.jisc.ac.uk/whatwedo/programmes/elearning/epi.aspx (Accessed: 3 November 2010).

Leitch, S. (2006) Prosperity for all in the global economy - world class skills (The Leitch Report). Available at: http://www.hmtreasury.gov.uk/media/6/4/leitch finalreport051206.pdf (Accessed: 3 November 10).

LSRC (2004) Learning styles and pedagogy in post-16 learning: a systematic and critical review. Available at: https://www.Isneducation.org.uk/user/order.aspx?code=041543\&src=XOWEB (Accessed: 3 November 2010).

NCIHE (1997) Higher education in the learning society (Report of the Dearing Committee). Available at: http://www.leeds.ac.uk/educol/ncihe/ (Accessed: 3 November 2010).

Peters, J. (2006) 'Researching student attitudes towards Personal Development Planning (PDP)', PDP and e-Portfolio UK Newsletter, Issue 7, March 2006. Available at: 
http://www.recordingachievement.org/news-and-events/publications/pdpuk.html (Accessed: 3 November 2010).

Peters, J. and Tymms, M. (2010) 'Defining personal development planning: putting the personal in PDP?', PDP and e-Portfolio UK Newsletter, Issue 20, September 2010. Available at: http://www.recordingachievement.org/news-andevents/publications/pdpuk/item/pdp-uk-newsletters/issue-20.html (Accessed: 3 November 2010).

QAA (2000) Policy statement on a progress file for higher education. Available at: http://www.qaa.ac.uk/academicinfrastructure/progressFiles/archive/policystatement/ default.asp (Accessed: 3 November 2010).

QAA (2001) Guidelines for HE progress files. Available at: http://www.qaa.ac.uk/academicinfrastructure/progressFiles/guidelines/progfile2001. asp (Accessed: 3 November 2010).

QAA (2004) Postgraduate research programmes: section 1 of the code of practice for the assurance of academic quality and standards in higher education. Available at: http://www.qaa.ac.uk/academicinfrastructure/codeOfPractice/section1/postgrad2004 .pdf (Accessed: 3 November 2010).

QAA (2009) Personal development planning: guidance for institutional policy and practice in higher education. Available at:

http://www.qaa.ac.uk/academicinfrastructure/progressfiles/guidelines/pdp/pdpguide. pdf (Accessed: 3 November 2010).

Richardson, H. and Ward, R. (2007) Personalised learning plans in Lifelong Learning Networks. Available at: http://www.hefce.ac.uk/pubs/rdreports/2007/rd11 07/rd11 07.pdf (Accessed: 3 November 2010).

Roberts, G. (2002) SET for Success (Final Report of the Roberts Review). Available at: http://www.vitae.ac.uk/policy-practice/1393-3083/SET-for-Success-Final-Report-ofSir-Gareth-Roberts-Review.html (Accessed: 3 November 2010). 
Stefani, L., Mason, R. and Pegler, C. (2007) The educational potential of e-portfolios: supporting personal development and reflective learning. Abingdon: Routledge.

Strivens, J. (2007) A survey of e-pdp and e-portfolio practice in UK higher education. Available at:

http://www.heacademy.ac.uk/assets/York/documents/ourwork/tla/personal develop ment plan/survey of epdp and eportfolio practice in uk higher education.pdf (Accessed: 3 November 2010).

Strivens, J., Baume, D., Grant, S., Owen C., Ward, R. and Nicol, D. (2010) The role of eportfolios in formative and summative assessment practices: report of the JISCfunded Study. Available at: http://www.jisc.ac.uk/whatwedo/programmes/elearning/eportfolios/studyontheroleof eportfolios.aspx\#downloads (Accessed: 3 November 2010).

University of Bolton (2005) Personal Development Planning (PDP) for all students studying at the University of Bolton: the University framework. Available at: http://www.bolton.ac.uk/LEPDU/Documents/PDPFramework.pdf (Accessed: 3 November 2010).

University of Bristol (2009) Personal Development Planning (PDP) - guidance and resources for academic staff website. Available at: http://www.bris.ac.uk/esu/studentlearning/pdp/ (Accessed: 3 November 2010).

University of Manchester (2010) HEARing student voices website. Available at: http://www.campus.manchester.ac.uk/tlso/hearingstudentvoices/ (Accessed: 3 November 2010).

Vitae (2009) UK Researcher Development Framework (RDF). Available at: http://www.vitae.ac.uk/CMS/files/upload/Vitae-Researcher-development-frameworkpresentation-Oct-2009.ppt\#258 Slide 3 (Accessed: 3 November 2010).

Ward, R. and Jackson, N. (2001) Personal development planning: institutional case studies. York: LTSN Generic Centre. 
Ward R., Jackson, N. and Strivens, J. (2005) Progress files: are we achieving our goal? Available at:

http://www.recordingachievement.org/research/narn.html?view=item\&item id=397 (Accessed: 3 November 2010).

\section{Author details}

Rob Ward is the Director of the Centre for Recording Achievement (CRA) in the UK. Rob was a member of the Scoping Group on Measuring and Recording Student Achievement (2004-6) and is currently a core member of the Group charged to support the trial and anticipated implementation of the HEAR across UK higher education. He led the CRA contribution to the 'National Action Research Network on Researching and Evaluating Personal Development Planning and e-Portfolio'. He is a Visiting Professor at the University of Bolton.

Janet Strivens is an educational developer at the University of Liverpool and also Senior Associate Director of the CRA. Her interests include assessment, the development of the autonomous learner, collaborative learning and the uses of technology to support all these processes.

A registered educational charity and network organisation, CRA (http://www.recordingachievement.org) exists to 'promote awareness and understanding of the processes of recording achievement as an important element in improving learning and progression throughout the world of education, training and employment'. CRA is the only Associate Partner of the Higher Education Academy (UK), with a brief to support the implementation of high quality Personal Development Planning and e-Portfolio practice throughout higher education. It took a leading role in the revision of the sectoral Guidelines on Personal Development Planning (QAA, 2009). 